\title{
Effect of cement types on carbonation depth of concrete
}

\author{
Merah A*, Korichi Y, Khenfer M M
}

\footnotetext{
Ammar Telidji University, Civil Engineering Research Laboratory, Laghouat-Algeria.

* Corresponding Author: a.merrah@lagh-univ.dz
}

Received: 23-05-2020

Accepted: 29-07-2020

\begin{abstract}
Reinforced concrete as a building material is the most used in civil engineering structures. This one is exposed to several attacks (physical, chemical and mechanical). Among these attacks, we can cite the phenomenon of carbonation, which leads to corrosion of the reinforcements and consequently reduces the service life of reinforced concrete structures. In addition, this phenomenon generates additional repair costs, which can sometimes exceed the initial cost of the building. Furthermore, it depends on the type and class of cement, two main classes of cement are used for the formulation of concrete in Algeria, ordinary Portland cements and cements with additions.

This paper enters in the context of sustainable development, in order to study the behavior of these two types of cements against accelerated carbonation.

For this purpose, two concrete compositions (based on ordinary Portland cements and cements with additions) were formulated, from these two formulations, samples were made in order to subject them to accelerated carbonation in a chamber rich in $\mathrm{CO} 2$ according to the recommendations of the AFPC-AFREM.

The results obtained clearly show that concretes based on ordinary Portland cements (OPC) are less sensitive to the phenomenon of carbonation compared to concretes based on blended cements.
\end{abstract}

Key words: sustainability; reinforced concrete; OPC cement; blended cement, durability, accelerated carbonation.

\section{Introduction}

Reinforced concrete is widely used in the world for the realization of structures in all fields of civil engineering, the absolute need to protect this material against atmospheric aggressions is very necessary. Among these attacks, we can mention the concrete carbonation.

Moreover, Concrete as a cementitious material is highly sensitive to the phenomenon of carbonation, which is due to the penetration of atmospheric carbon dioxide through the porosity of the concrete surface. This gas reacts with the portlandite $\left(\mathrm{Ca}(\mathrm{OH})_{2}\right)$ by lowering the $\mathrm{pH}$ of the interstitial solution from 13 to 9. This decrease in $\mathrm{pH}$ causes the reserve of portlandite (component responsible for durability) to be consumed and Once the coating of concrete is carbonated, the steel reinforcement initially protected may corrode. The damage associated with this phenomenon corresponds to cracks by the degradation of the concrete coating, by the formation of iron oxides and hydroxides on the reinforcements These consequences of carbonation can have an impact on the bearing capacity of structural elements.

In addition, most of the civil engineering structures realized in Algeria are made of reinforced concrete, these structures are mainly based on two classes of cements, ordinary Portland cements OPC and blended cement.

Many researchers have been interested in the effect of cement additions on the concrete carbonation, Papadakis et al. (1992) developed a mathematical model that controls the evolution of carbonation in time with $50 \%$ relative humidity; this model has been extended to cover the case of carbonation of the coating system (lime cement) and concrete, this model has 
been validated for concrete based on ordinary Portland cement (OPC) and on blended cement with pozzolanic additions. Elsewhere, Dakhmouche Chabil (2009) shows that the carbonation depth of concrete samples decreases if additions (silica fume and fly ash with a high and low calcium content) replace a quantity of aggregates and increases if additions replace a quantity of cement.

Moreover, Dakhmouche Chabil (2009) concludes that the carbonation depth in mortars based on blended cement is higher than the depth of carbonation mortars based on OPC cements. In the same context, Sisomphon and Franke (2007) show that additions in volume (pozzolan materials) increases the carbonation rate with increasing $\mathrm{W} / \mathrm{C}$ ratio, and concluded that the depth of accelerated carbonation (chamber riched of $3 \% \mathrm{CO}_{2}$ ) is 10 times higher than under natural exposure conditions. According to Kulakowski et al. (2009), a rate higher than 10\% additions in silica fume increases the potential for carbonation. Moro et al. (2011) and Phung et al. (2015) studied the effect of limestone fillers on the microstructure and permeability due to carbonation of cement pastes conditionally controlled $\mathrm{CO}_{2}$ pressure, it shows that the carbonation samples $(\mathrm{RH}=65 \%)$ is fast during the first hours while it decreases significantly if the relative humidity increases, this study shows that on the additional carbonation of portlandite, $\mathrm{CSH}$ are also carbonated.

Moreover, Morandeau et al (2015) and Sideris et al. (2006) show that the fly ash additions (about 30\%) to ordinary Portland cement with a ratio of W / C in order of 0.6 , the cement pastes develop coarse capillary pores which for extensive drying occur even if the total porosity decreases.

This work inscribed in a sustainable development approach, which focus to study the behavior of concretes based on OPC cement and blended cements (42.5 CEM II / B) produced in Algeria, subjected to the accelerated carbonation. This work studies the effect of the class of cement on the evolution of the accelerated carbonation depth, two concrete formulations were made based on both classes of cement (OPC cement 42.5 and blende cements CEM II / B) from the two concrete formulations, prismatic test samples $7 \times 7 \times 28 \mathrm{~cm}$ were made, and they were subjected to the accelerated carbonation test in a chamber enriched in $\mathrm{CO}_{2}$ as recommended by AFPCAFREM (Ollivier, 1997), carbonation depth measurements were carried out by spraying phenolphthalein at $4,7,14,28,42$ and 56 days

For this study, the choice is oriented for the cements produced in Algeria, the OPC cement CEM I and cement CEM II 42.5 / B.

\section{Experimental program}

\subsection{Concrete formulation}

The cement used for the $1^{\text {st }}$ concrete formulation is ordinary Portland cement (OPC) CEM I 42.5,

Table 1 shows the chemical and physical characteristics of this cement.

Table 1. Physical and chemical characteristics of the OPC cement CEM I 42.5

\begin{tabular}{|c|c|c|c|c|c|c|c|c|c|}
\hline \multirow{2}{*}{$\begin{array}{c}\text { CEMI } \\
42.5\end{array}$} & $\mathrm{SiO}_{2}$ & $\mathrm{Al}_{2} \mathrm{O}_{3}$ & $\mathrm{Fe}_{2} \mathrm{O}_{3}$ & $\mathrm{CaO}$ & $\mathrm{MgO}$ & $\mathrm{K}_{2} \mathrm{O}$ & $\mathrm{Na}_{2} \mathrm{O}$ & $\mathrm{SO}_{3}$ & $\begin{array}{c}\text { S.s } \\
\mathrm{cm}^{2} / \mathrm{g}\end{array}$ \\
\hline & $20-23$ & $\begin{array}{l}4.07- \\
4.80\end{array}$ & $\begin{array}{l}4.70- \\
5.40\end{array}$ & $\begin{array}{l}62- \\
65\end{array}$ & $\begin{array}{c}0.71- \\
1.22\end{array}$ & $\begin{array}{c}0.35- \\
0.50\end{array}$ & $0.07-0.18$ & $\begin{array}{l}1.00- \\
1.45\end{array}$ & $\begin{array}{l}2500- \\
3263\end{array}$ \\
\hline
\end{tabular}

*S.s : Specific surface

The used Cement for the $2^{\text {nd }}$ concrete formulation is the blended cement CEM II 42.5 / B, Table 2 shows the chemical and physical characteristics of this cement. 
Table 2. Chemical and physical characteristics of the blended cement CEM II/B

\begin{tabular}{|c|c|c|c|c|c|c|c|c|c|}
\hline $\begin{array}{c}\mathrm{CEM} \\
\mathrm{II} / \mathrm{B}\end{array}$ & $\mathrm{SiO}_{2}$ & $\mathrm{Al}_{2} \mathrm{O}_{3}$ & $\mathrm{Fe}_{2} \mathrm{O}_{3}$ & $\mathrm{CaO}$ & $\mathrm{MgO}$ & $\mathrm{K}_{2} \mathrm{O}$ & $\mathrm{Na}_{2} \mathrm{O}$ & $\mathrm{SO}_{3}$ & $\begin{array}{c}\mathrm{S.s} \\
\mathrm{cm}^{2} / \mathrm{g}\end{array}$ \\
\cline { 2 - 10 } 42.5 & 20.58 & 4.90 & 4.70 & 62.8 & 0.63 & 0.42 & $0.07-0.18$ & 2.28 & 3700 \\
\hline
\end{tabular}

*S.s : Specific surface

The used method for the two concrete formulations is the Dreux Gorisse method. Two used classes of gravel were (3-8mm, 8-15 mm), with absolute density equal to $2700 \mathrm{~kg} / \mathrm{m}^{3}$, and the used sand has an absolute density of $2400 \mathrm{~kg} / \mathrm{m}^{3}$.

The results of these formulations show that the cement content in concrete was $408 \mathrm{~kg} / \mathrm{m}^{3}$ for the both concrete formulations, the slump cone was $11 \mathrm{~cm}$. The compressive strength at 28 days of the formulated concrete is $30 \mathrm{MPa}$ (the most used concrete in Algeria). The W / C ratio is around 0.52 .

Table 3. Results of the concrete composition of the concrete formulation (OPC cement CEM I 42.5)

\begin{tabular}{|c|c|c|c|c|c|}
\hline Sand (0-5) kg & Gravel 3-8 (kg) & Gravel 8-15 (kg) & Ciment CEM I 42.5 (kg) & Water (l) & W/C \\
\hline 708 & 115 & 933 & 408 & 211 & 0.52 \\
\hline
\end{tabular}

Table 4. Results of the concrete composition of the 2nd formulation (CEM II 42.5 / B)

\begin{tabular}{|c|c|c|c|c|c|}
\hline Sand (0-5) kg & Gravel 3-8 $(\mathrm{kg})$ & Gravel 8-15 $(\mathrm{kg})$ & Ciment CEM II 42.5/B $(\mathrm{kg})$ & Water $(\mathrm{l})$ & W/C \\
\hline \hline 708 & 115 & 933 & 408 & 211 & 0.52 \\
\hline
\end{tabular}

The compressive strength at 28 days of the formulated concrete is $30 \mathrm{MPa}$, the $\mathrm{W} / \mathrm{C}$ ratio is about of 0.57 . Figure 1: show the DRX mineralogical composition of used limestone gravel

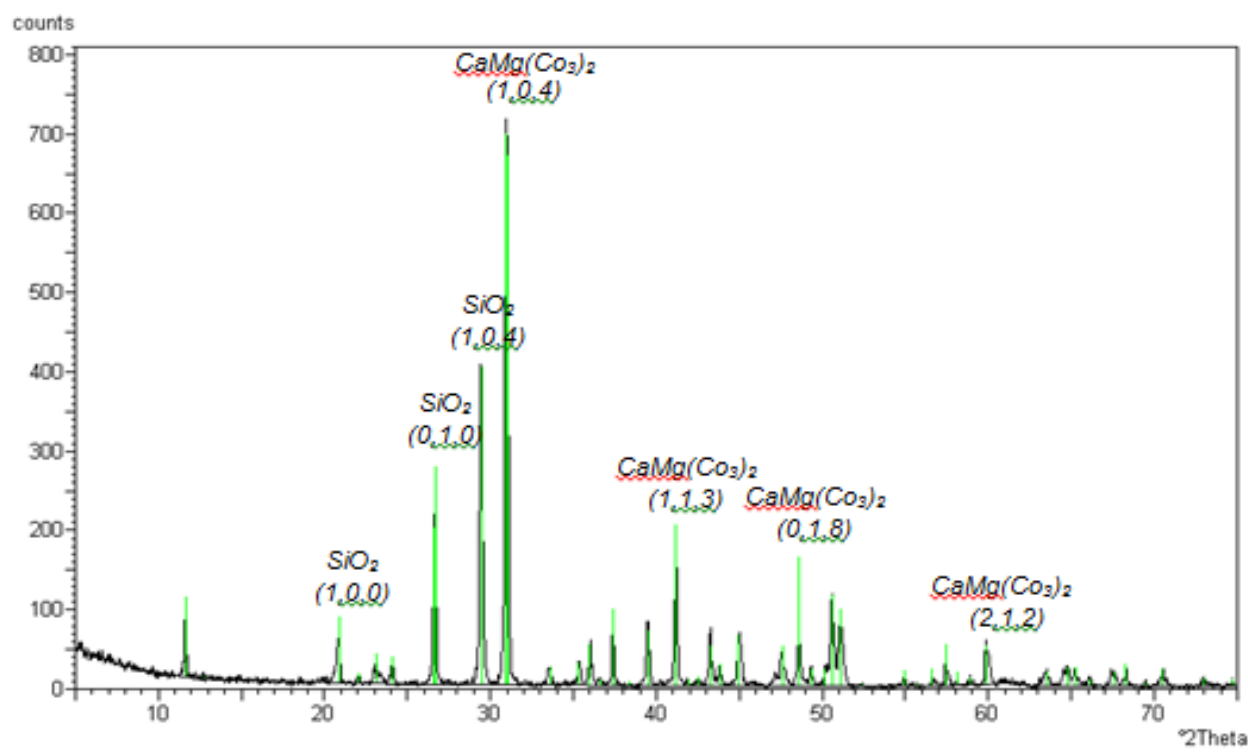

Fig. 1. Mineralogical composition of used limestone gravel

This analysis allowed to identify the nature of the component elements limestone gravel, they are all dolomite $\mathrm{CaMg}\left(\mathrm{CO}_{3}\right)_{2}$ and some quartz elements $\mathrm{SiO}_{2}$.

\subsection{Preparation of samples and conservations conditions for accelerated carbonation test}

The prismatic samples $7 \times 7 \times 28 \mathrm{~cm}$ were confectioned according the procedure recommended by AFPC-AFREM (Ollivier, 1997). For both formulations, samples were made to undergo accelerated carbonation test, and they will be used for the carbonated concrete depth 
measurements, other samples will be used to monitor evolution of the mass during the test. All these samples were cured in water for 28 days

Before initiating accelerated carbonation test, the procedure specified in AFREM recommendations follow two phases: the first phase consist to saturate samples in the water. At the end of this phase, the samples will be weighed, dried for two days in an oven set at a temperature of $40 \pm 2 \mathrm{C}^{\circ}$, then they are still weighed, once before their introduction into the chamber of the accelerated carbonation.

\subsection{Accelerated carbonation test}

The test procedure adopted is the one recommended by the AFPC AFREM (Ollivier, 1997) which consist to place (after 28 days of curing and drying) the prismatic samples $7 \times 7 \times 28 \mathrm{~cm}$ (Figure 2) of two concrete formulations in the chamber of accelerated carbonation $\left(50 \% \mathrm{CO}_{2}+50 \%\right.$ Air) ( Figure 3), Regulated at a temperature of $20^{\circ} \mathrm{C}$ and a relative humidity of $65 \pm 5 \%$.

All these samples were maintained in the chamber of accelerated carbonation for a period of 90 days.

For each formulations, samples were removed from the chamber of accelerated carbonation at different ages: 4, 7, 14, 28, 42, 56 and 90 days, and they were sliced in two parts (figure 5) and a measurements of carbonation depth (by spraying the solution of phenolphthalein, $(1 \%$ phenolphthalein in 70\% ethyl alcohol) were executed with according to RILEM recommendations CPC-18 (1988).

Carbonated depth corresponds to the distance between the outer surface of the concrete and the coloring front (Figure 4), the uncarbonated concrete takes a pink color and the carbonated concrete is not colored (Figure 5). This method is based on the change of the PH value, initially around 13 for the uncarbonated concrete and passes to 9 for the carbonated concrete, five distances are determined for each side of the test samples. The values of carbonation depth are given in $\mathrm{mm}$.

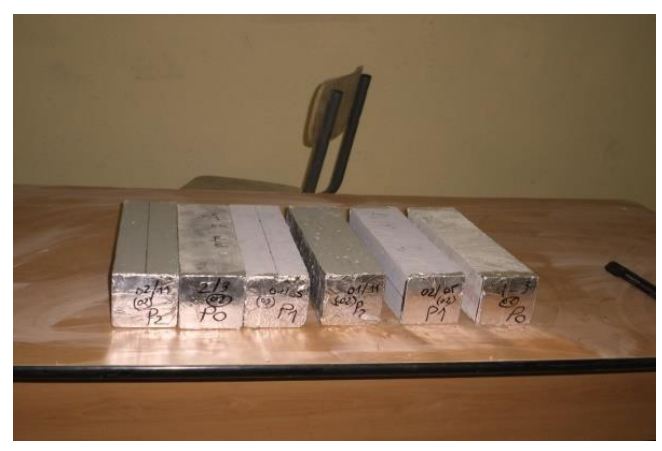

Fig. 2. Prismatic samples $7 \times 7 \times 28 \mathrm{~cm}$
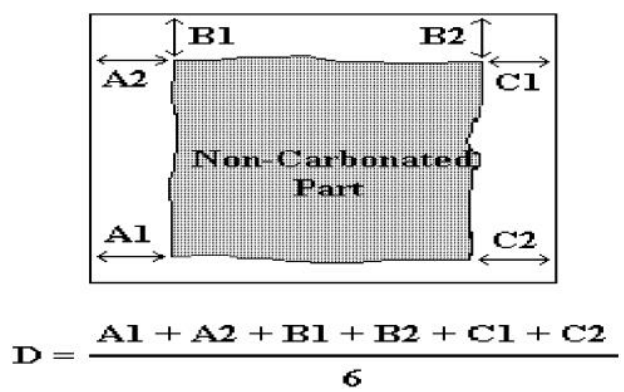

Fig. 4. Method to measure of carbonation depth

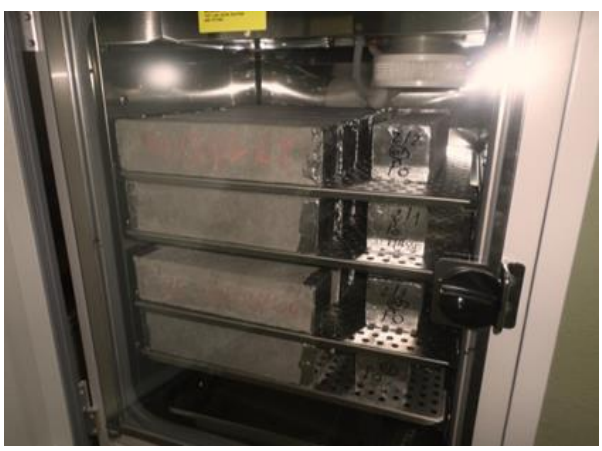

Fig. 3. Samples into the carbonation chamber

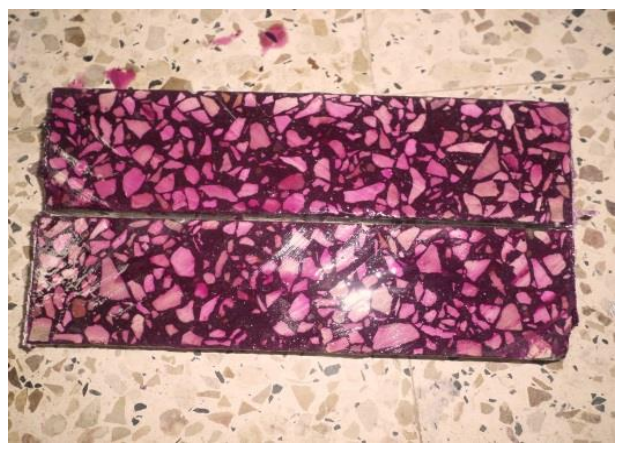

Fig. 5. Detection of the carbonated zone 


\section{Results and discussions}

\subsection{DRX test}

This technique essentially qualitative, used to differentiate varieties of the same crystallographic mineral such as portlandite and calcium carbonate (calcite). However, it does not identify the semi-crystalline or amorphous compounds such as amorphous portlandite or amorphous newly formed calcium carbonates.

This method involves bombarding a sample (isotropic homogeneous powder consisting of tiny crystals welded together) with X-rays and recording the X-ray intensity which is redistributed according to the orientation in space. The scattered X-rays interfere with each other, the intensity then has maxima in certain directions. There is a diffraction phenomenon.

The detected intensity is then drawn as a function of the beam deflection angle. The obtained curves are called diffractograms.

Figures 6 and 7, show diffractograms for an angle range (0 to 26 degrees), for the two types of carbonated concrete after 90 days in the carbonation chamber.

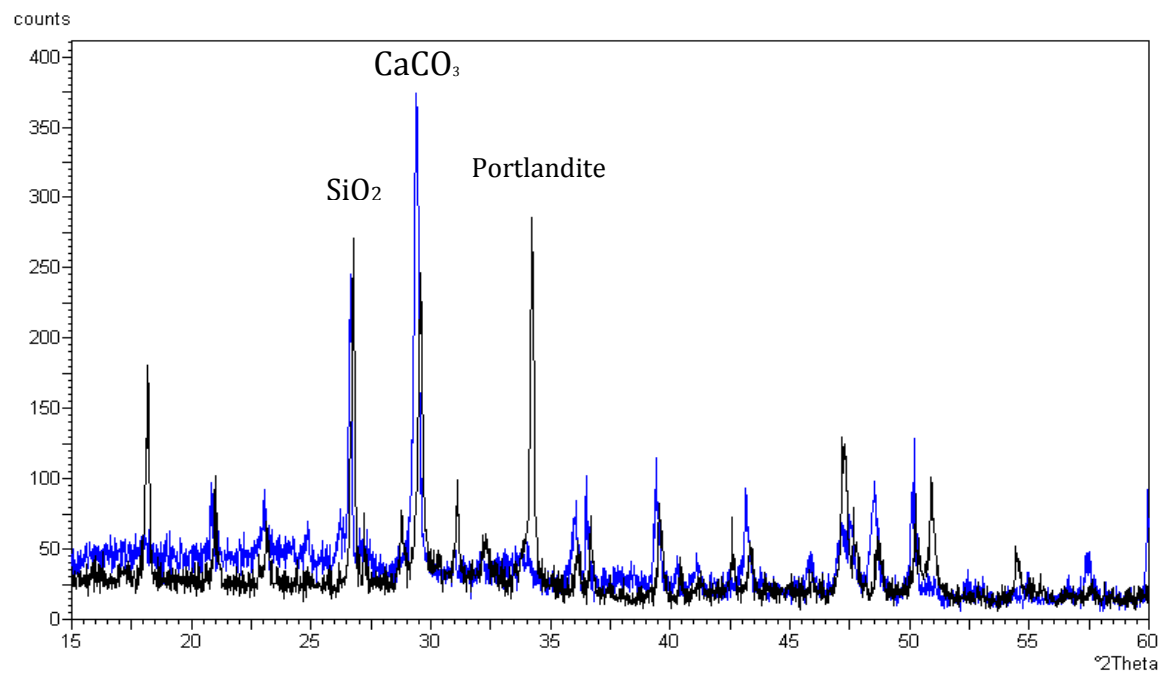

Fig. 6. DRX analyzes on the carbonated (black)and uncarbonated (blue) samples for the $2^{\text {nd }}$ concrete formulation (based on Blended cement)

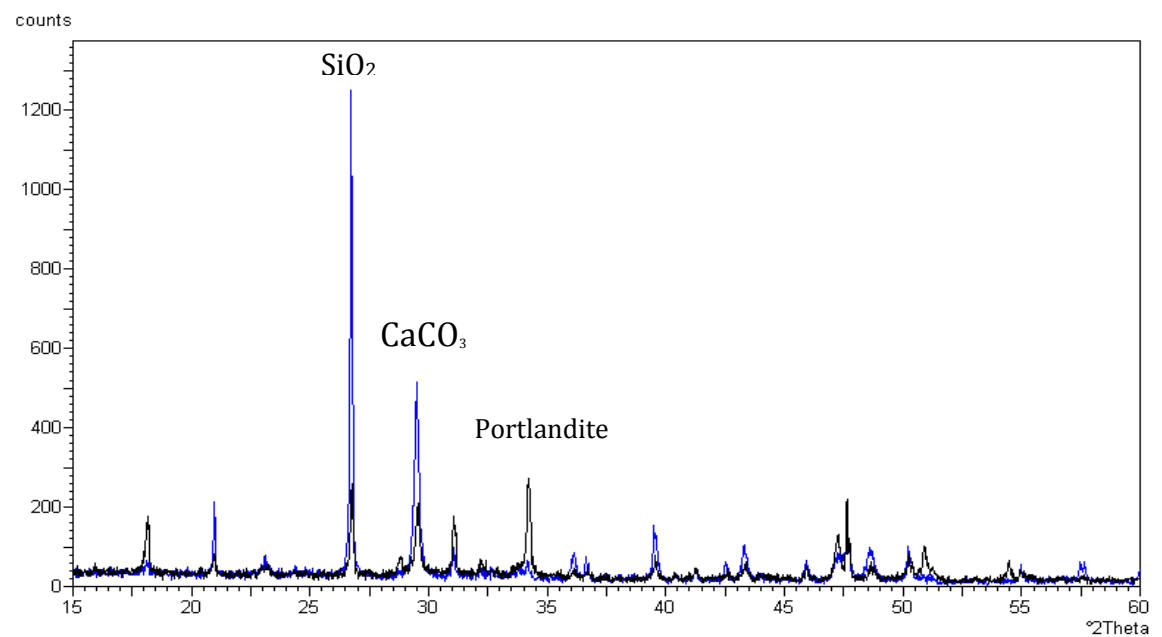

Fig. 7. DRX analyzes on the carbonated (black)and uncarbonated (blue) samples for the $1^{\text {st }}$ concrete formulation (based on OPC cement) 
In order to confirm the measures of carbonation depth obtained with the method of the spraying phenolphthalein, the x-ray diffraction was used for the detection of the new formed products after carbonation and compared to controlled samples for the two concrete formulations.

For both concrete formulations of carbonated samples, we observe that the reserve of portlandite was higher in the concrete made with OPC cement compared to the samples of concrete made with blended cement. This can be explained that the concrete made with blended cement is more sensitive to carbonation compared with samples made with OPC cement. This constating is caused that the OPC cement has a high reserve of portlandite compared to blended cement. In another way, the composition of the two cements is different.

\subsection{Impact of the cement type on the accelerated carbonation}

Figure 8 shows the results of the accelerated carbonation test for the test samples of the two concrete formulations. From this figure, it can be seen that the $1^{\text {st }}$ concrete formulation based on the OPC cement is less sensitive to carbonation phenomenon that the second one.

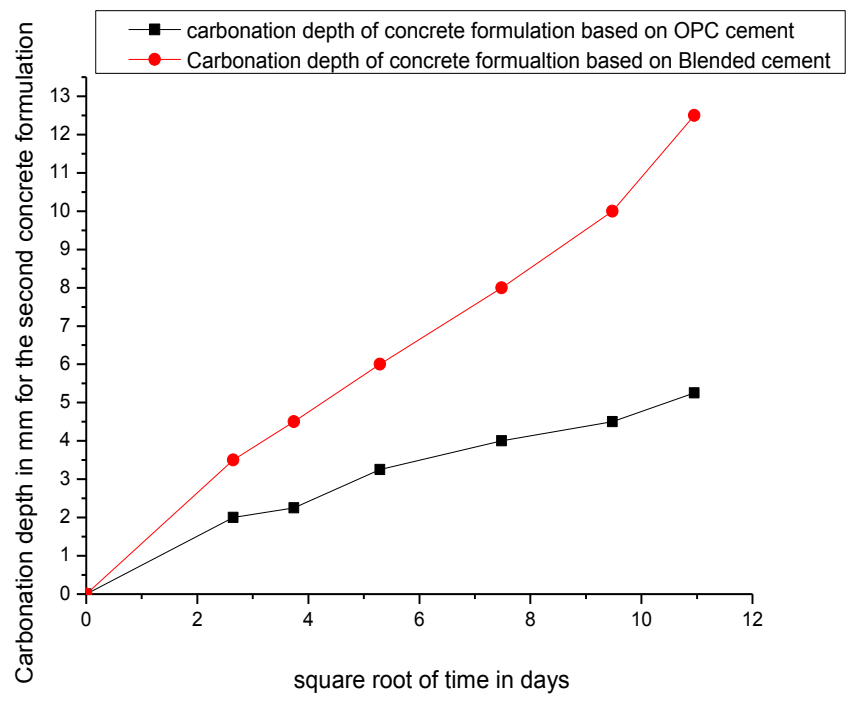

Fig. 8. : Carbonation depth (concrete based on OPC cement and concrete based on blended cement)

The $1^{\text {st }}$ concrete formulation gives a better protection for the concrete against the carbonation phenomenon compared with the $2^{\text {nd }}$ concrete formulation. These results are in agreement with those obtained by Sisomphon and Franke (2007).

In addition, for concrete samples of the 1st formulation, it was found that the depth of carbonation is low during the first days and increase from the 7th day, but it is still inferior to the depth of carbonation samples of the $2^{\text {nd }}$ concrete formulation; This is due to the fact that during the first days the relative humidity is not stable within the chamber due to water exchange between the concrete and the relative humidity inside the chamber of accelerated carbonation.

\subsection{Evolution of mass during the accelerated carbonation test}

Figure 9 shows the evolution of the mass during accelerated carbonation test for samples of the two concrete formulations. 


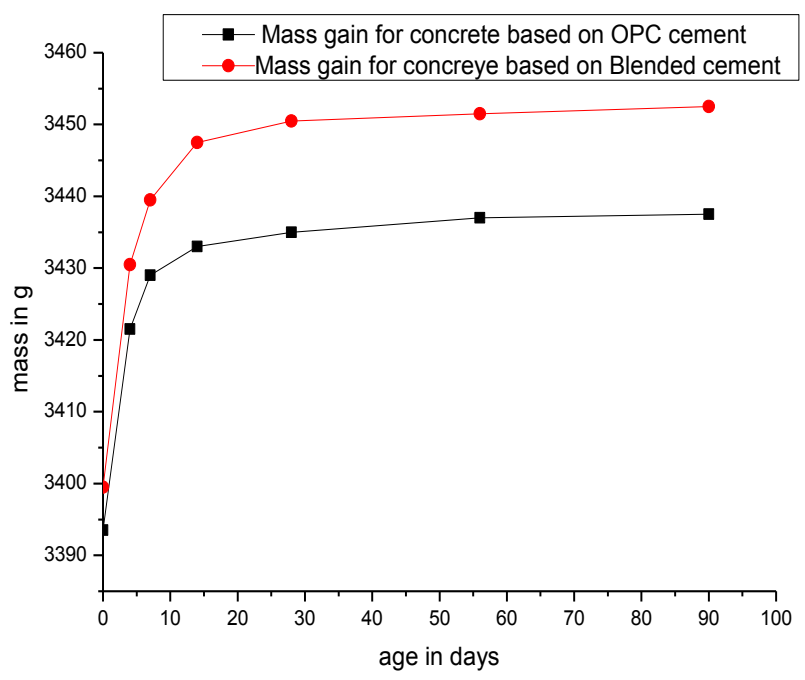

Fig. 9. Mass gain during the accelerated carbonation test

From this figure, it was found a mass gain in the early days of the test, especially for the samples of the 2nd concrete formulation; this can be explained by the fact that in the early days the relative humidity varies depending on the water exchange between the concrete and the atmosphere in the accelerated carbonation chamber. Then the relative humidity stabilizes at a value of $65 \pm 5 \%$. Moreover, this figure has the same form for the two concrete formulations, which agree with the results of AFREM crossover tests. We also note that the mass gain during the accelerated carbonation test is less important for samples from the 1st formulation of concrete, this is due that the cement CEMII / $42.5 \mathrm{~B}$ of the second formulation contains additions.

These results confirm that the use of the 1st formulation of concrete based on cement CEM I 42.5 OPC gives a supplementary protection against the carbonation that the $2^{\text {nd }}$ concrete formulation based on blended CEM II 42.5 /B

\section{Conclusion}

In the present work, a concrete composition B30 was made (2 fractions of gravel). Samples from both concrete formulations were made and submitted to the accelerated carbonation test.

We can draw the following conclusions:

1. The use of the OPC cement for the confectioning of reinforced concrete structures minimizes carbonation depth compared to concretes based on blended cement CEM II / B 42.5 .

2. It was found that a low mass change for concrete samples-based cements CEM I / 42.5, compared to concretes-based cements CEM II / 42.5 B.

3. As regards the accelerated carbonation test, it was also found that the water exchange between the concrete and the atmosphere in the chamber do not stabilize after the $7^{\text {th }}$ day.

4. The results show that the formulation of concrete-based OPC cement is less sensitive to carbonation phenomenon compared to the concrete formulation based on cements CEM II / $42.5 \mathrm{~B}$. 


\section{References}

Dakhmouche Chabil, F., Z. (2009). Carbonatation de bétons adjuvantés à base de ressources locales algériennes (PhD Thesis). Orléans.

CPC-18, R. R. (1988). Measurement of hardened concrete carbonation depth. Materials and structures, 21(126), 453-455.

Kulakowski, M. P., Pereira, F. M., \& Dal Molin, D. C. (2009). Carbonation-induced reinforcement corrosion in silica fume concrete. Construction and building materials, 23(3), 1189-1195.

Morandeau, A., Thiéry, M., \& Dangla, P. (2015). Impact of accelerated carbonation on OPC cement paste blended with fly ash. Cement and Concrete Research, 67, 226-236.

Moro, F. R., Ghomari, F., Boukli Hacène, M. A., Taleb, O., Loukili, A., \& Rosière, E. (2011). La carbonatation des bétons aux fortes additions calcaires, XXIXe Rencontres Universitaires de Génie Civil, Tlemcen, Algeria.

Ollivier, J. P. (Ed.). (1997). Essai de carbonatation accéléré, mesure de l'épaisseur de béton carbonate. Durabilité des Bétons, Méthodes Recommandées pour la Mesure des Grandeurs Associées à la Durabilité, 153-158.

Papadakis, V. G., Fardis, M. N., \& Vayenas, C. G. (1992). Effect of composition, environmental factors and cement-lime mortar coating on concrete carbonation. Materials and structures, 25(5), 293-304.

Phung, Q. T., Maes, N., Jacques, D., Bruneel, E., Van Driessche, I., Ye, G., \& De Schutter, G. (2015). Effect of limestone fillers on microstructure and permeability due to carbonation of cement pastes under controlled CO2 pressure conditions. Construction and Building Materials, 82, 376-390.

Sideris, K. K., Savva, A. E., \& Papayianni, J. (2006). Sulfate resistance and carbonation of plain and blended cements. Cement and Concrete Composites, 28(1), 47-56.

Sisomphon, K., \& Franke, L. (2007). Carbonation rates of concretes containing high volume of pozzolanic materials. Cement and Concrete Research, 37(12), 1647-1653. 